\title{
3 Research Square

\section{Malaria Prevalence and Performance of Diagnostic Tests Among Hospitalized Fever Patients in Zanzibar}

Annette Onken ( $\sim$ annetteonken@yahoo.com )

University of Bergen: Universitetet i Bergen https://orcid.org/0000-0003-1712-896X

Christel Gill Haanshuus

Haukeland University Hospital: Haukeland Universitetssjukehus

Mohammed Miraji

Mnazi Mmoja Referral Hospital

Msafiri Marijani

Mnazi Mmoja Referral Hospital

Kibwana Omar Kibwana

Mnazi Mmoja Referral Hospital

Khamis Ali Abeid

Mnazi Mmoja Referral Hospital

Kristine Mørch

University of Bergen: Universitetet i Bergen

Marianne Reimers

Haukeland University Hospital: Haukeland Universitetssjukehus

Nina Langeland

University of Bergen: Universitetet i Bergen

Fredrik Müller

Oslo University Hospital: Oslo Universitetssykehus

Pål Arne Jenum

Vestre Viken Hospital Trust: Vestre Viken HF

Bjørn Blomberg

University of Bergen: Universitetet i Bergen

\section{Research}

Keywords: Malaria, prevalence, surveillance, microscopy, point-of-care diagnostic tests, polymerase chain reaction, Zanzibar, Tanzania, Eastern Africa

Posted Date: May 5th, 2021 
DOl: https://doi.org/10.21203/rs.3.rs-467425/v1

License: (c) (1) This work is licensed under a Creative Commons Attribution 4.0 International License. Read Full License 


\section{Abstract}

Background: Control efforts in Zanzibar reduced the burden of malaria substantially from 2000 to 2015, but re-emergence of falciparum malaria has been observed the last years. This study evaluated the prevalence of malaria and performance of routine diagnostic tests among hospitalized fever patients in a 1.5 years period in 2015 and 2016.

Methods: From March 2015 to October 2016, pediatric and adult patients hospitalized with acute undifferentiated fever at Mnazi Mmoja Hospital, Zanzibar were included. The malaria prevalence was assessed by polymerase chain reaction (PCR), rapid diagnostic test (RDT) and routine microscopy.

Results: Malaria prevalence was 8\% (67/820). All cases identified by PCR had Plasmodium falciparum infection, except for one P. ovale. Compared to PCR, the RDT had sensitivity of $64 \%(36 / 56)$, specificity 98\% (561/575), positive predictive value (PPV) 72\% (36/50) and negative predictive value (NPV) $97 \%$ (561/581). Microscopy had a sensitivity of 50\% (18/36), specificity $99 \%(251 / 254)$, PPV $86 \%(18 / 21)$ and NPV 93\% (251/269) compared to PCR.

Conclusions: A high malaria prevalence was identified compared to previous studies in Zanzibar. Microscopy showed higher PPV than RDT in this study. Both RDT and microscopy had low sensitivity compared to PCR. However, low parasitemia identified only by PCR in a semi-immune individual could be coincidental and may not be the cause of the presenting symptoms. To achieve malaria elimination in Zanzibar, PCR-based surveillance is suitable to guide control and elimination efforts.

\section{Full Text}

This preprint is available for download as a PDF.

\section{Figures}




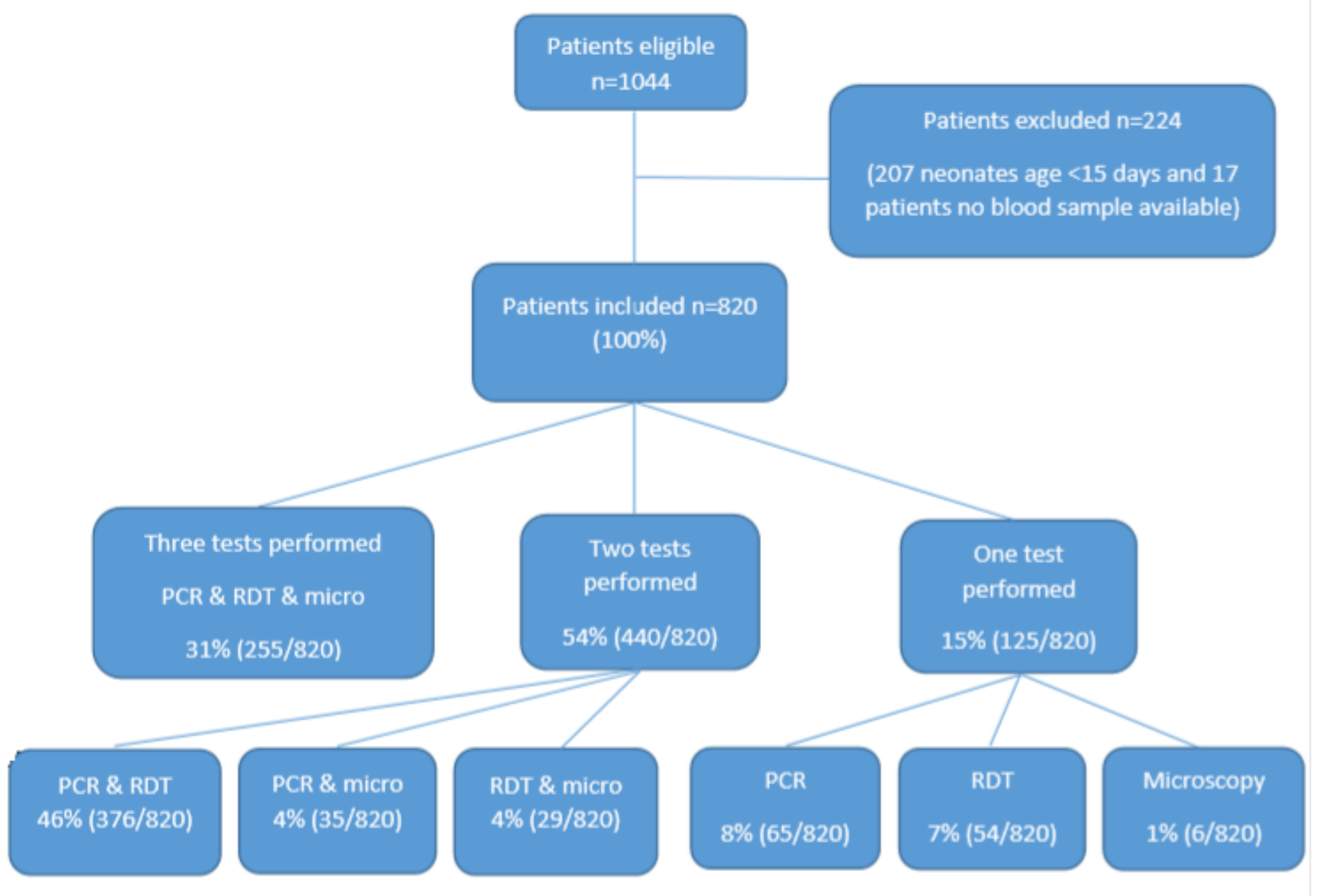

Figure 1

Patients included and analyses performed 
Figure 2. Parasitemia by RDT and microscopy result
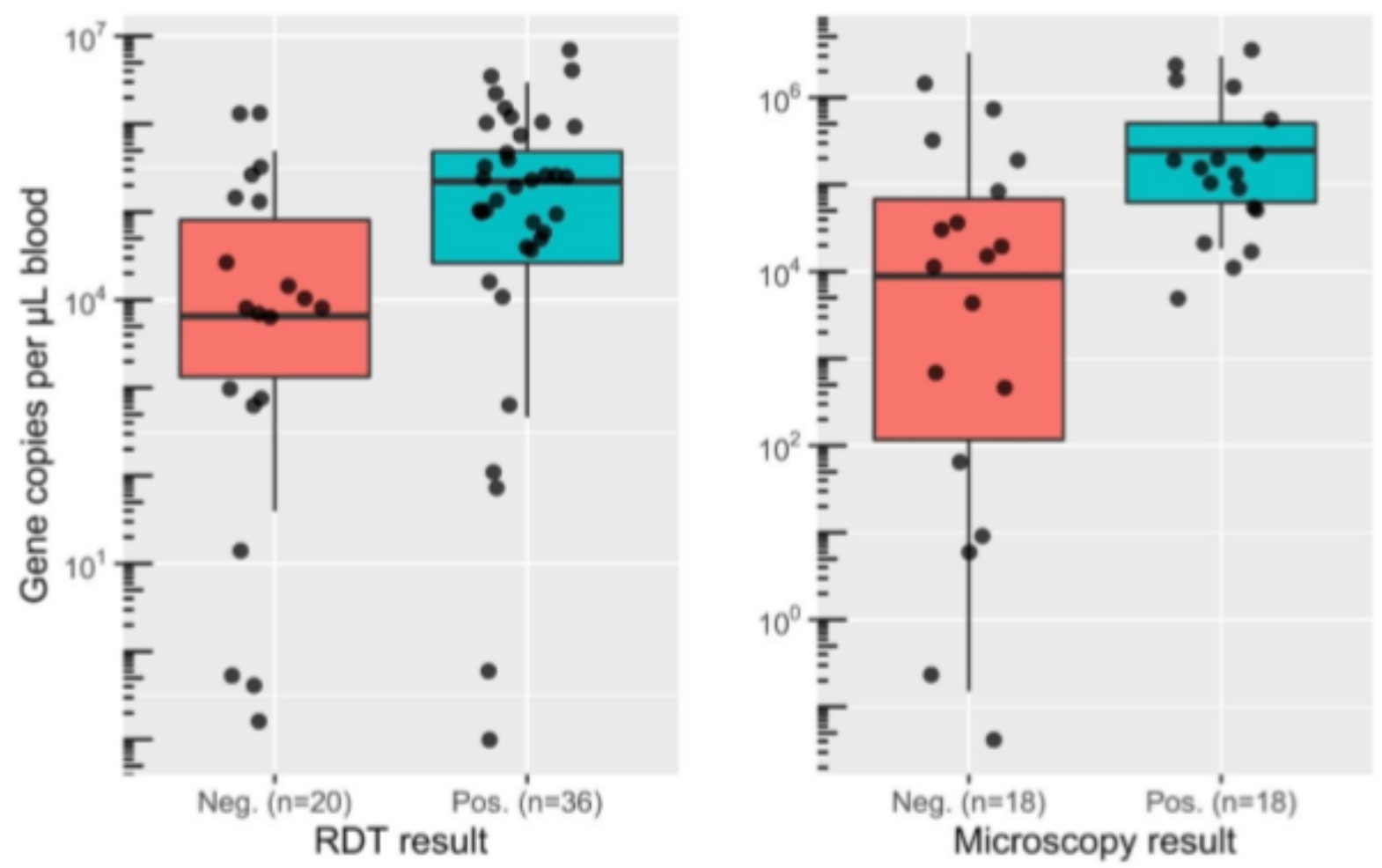

Figure 2

Quantitation of parasitemia by real-time PCR by diagnostic modalities expressed as log-transformed values of copies per $\mu \mathrm{L}$ blood. Dots represent individual observations. Number tested in brackets. Micro+, microscopy positive; Micro-, microscopy negative; RDT+, rapid diagnostic test positive; RDT-, rapid diagnostic test negative. 
Figure 3. Malaria cases by age groups

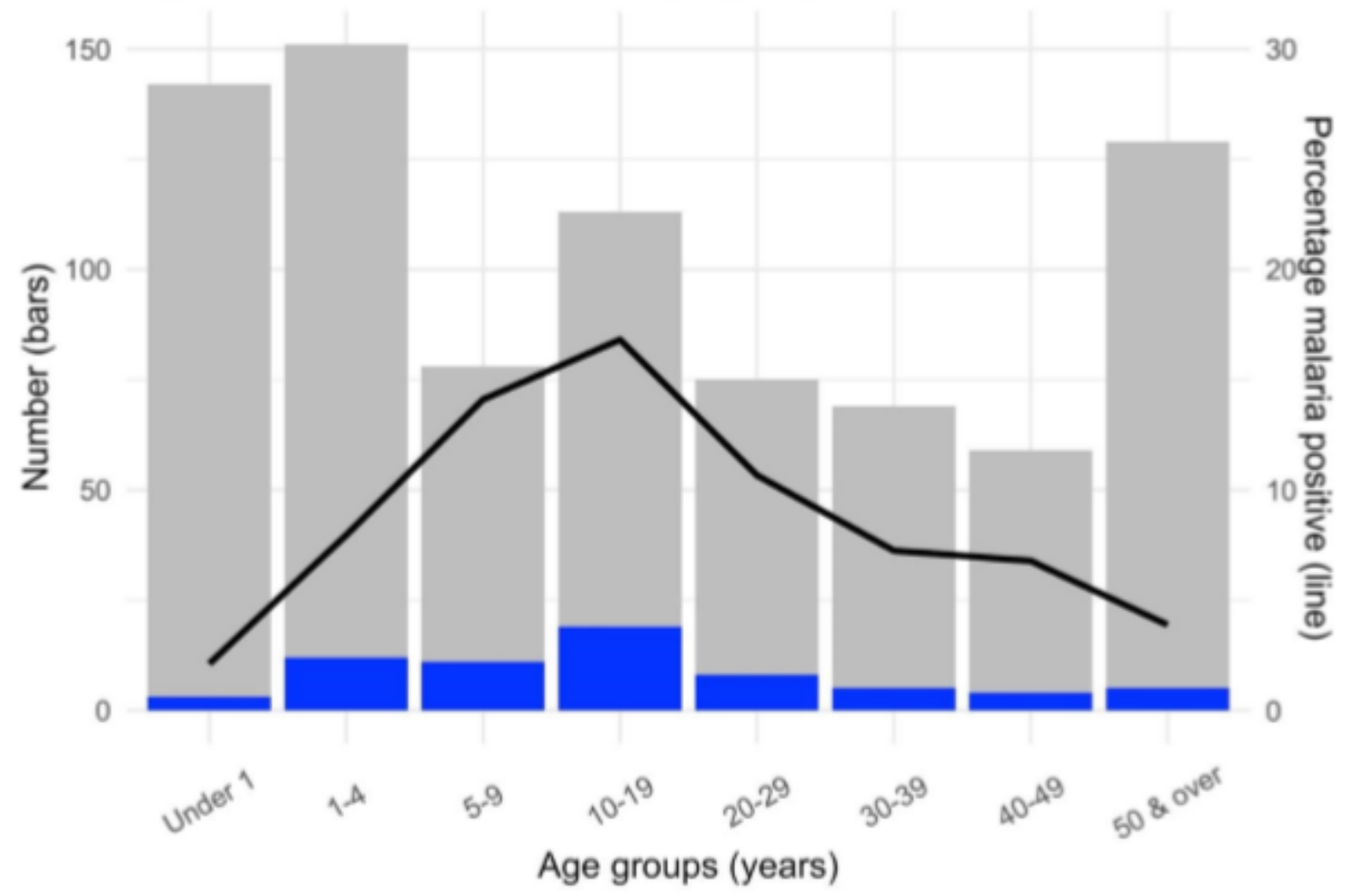

Figure 3

Number of malaria patients (blue bars) among 820 febrile patients (grey bars) and percentage positive (line) in different age groups. 


\section{Fig 4. Monthly number of malaria cases and rainfall}

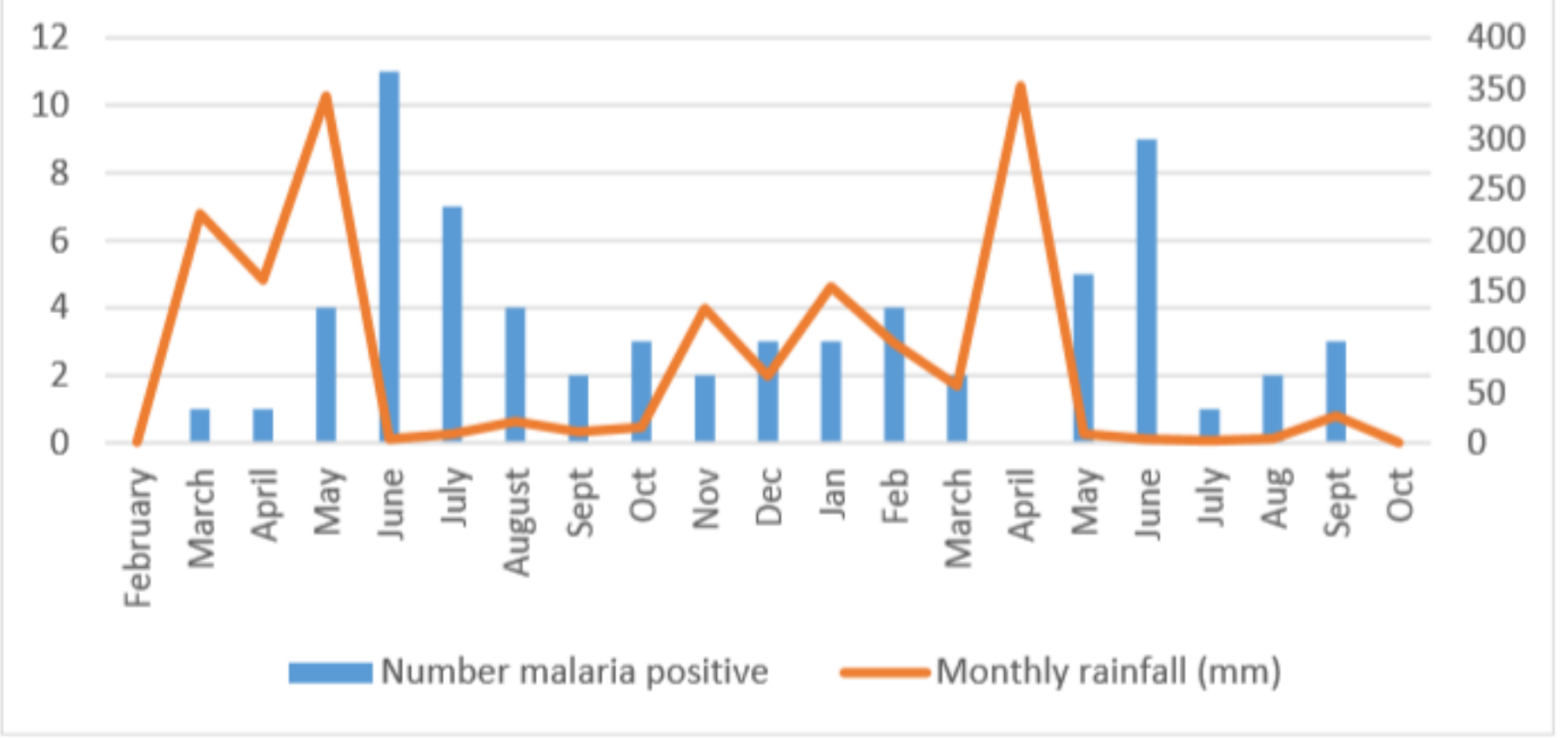

\section{Figure 4}

Monthly number of malaria cases and monthly rainfall from February 2015 to October 2016. Rainfall data for Dar es Salaam from the Tanzanian Meteorological Agency (TMA) $(28,29)$. Study start March 17 , 2015, study end October 4, 2016. 